
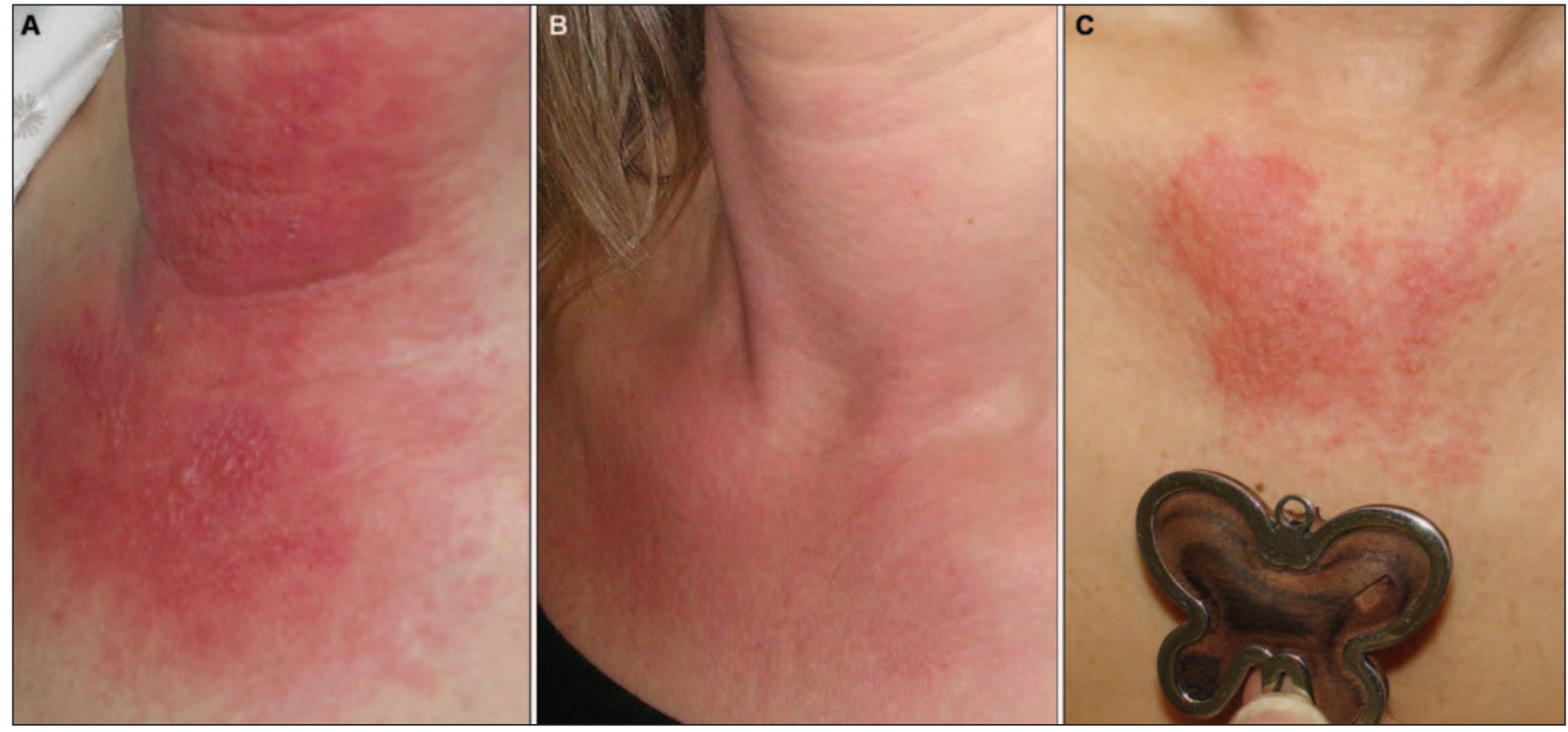

Figure 1: Allergic contact dermatitis on the anterior neck and chest of a 37-year-old woman (panel A), and its resolution after therapy (panel B). An eruption resembling the shape of an ebony pendant developed on the same region during patch testing (panel C).

\title{
Patch test triggering recurrence of distant dermatitis: the flare-up phenomenon
}

A 37-year-old woman presented with a pruritic, vesiculobullous eruption on her neck in the region of an ebony pendant. Acute allergic contact dermatitis was suspected and treated with oral prednisone and hydroxyzine (Figure 1A and Figure 1B). Two months later, we performed a patch test on her back using scrapings from the pendant dissolved in a 5\% petrolatum solution. Readings at 48 and 96 hours were strongly positive and confirmed allergic contact dermatitis. Coinciding with the positive results of the patch test, an eruption resembling the butterfly shape of her pendant developed on her chest (Figure 1C). The wood of the pendant was identified as Diospyros ebenum J. König.

Plants belonging to the Ebenaceae family have been described as a cause of occupational allergic contact dermatitis in woodworkers ${ }^{1}$ and musicians. ${ }^{2}$ Like other naturally occurring quinones, macassar quinone, the only known allergen of ebony, has a high sensitizing potential. However, the incidence of contact dermatitis from ebony is lower than might be expected, mainly because these compounds are found largely in the heartwood of mature trees.

The pathogenesis of flare-up during patch testing is not fully understood. Once the allergen has penetrated the tested skin and entered the blood stream, it may reactivate specific memory $\mathrm{T}$ cells persisting in the previous area of contact. $^{3}$

Clinical images are chosen because they are particularly intriguing, classic or dramatic.

Submissions of clear, appropriately labelled high-resolution images must be accompanied by a figure caption and the patient's written consent for publication. A brief explanation (300 words maximum) of the educational significance of the images with minimal references is required.

\section{Daniele Torchia MD}

Department of Dermatological Sciences

Department of Experimental Pathology and Oncology

University of Florence

Chiara Capretti PhD

Benedetto Pizzo PhD CNR-IVALSA

Trees and Timber Institute Sesto Fiorentino

Stefano Francalanci MD

Department of Dermatological Sciences

University of Florence

Florence, Italy

\section{REFERENCES}

1. Rackett SC, Zug KA. Contact dermatitis to multiple exotic woods. Am J Contact Dermat 1997;8:114-7.

2. Kuner N, Jappe U. Allergic contact dermatitis from colophonium, turpentine and ebony in a violinist presenting as fiddler's neck. Contact Dermatitis 2004;50:258-9.

3. Moed H, Boorsma DM, Tensen CP, et al. Increased CCL27-CCR10 expression in allergic contact dermatitis: implications for local skin memory. $J$ Pathol 2004;204:39-46. 